\title{
Preparation of Silver Nanostructures from Bicontinuous Microemulsions
}

\author{
M. A. Pedroza-Toscano, ${ }^{1}$ M. Rabelero-Velasco, ${ }^{1}$ R. Díaz de León, ${ }^{2}$ H. Saade, ${ }^{2}$ \\ R. G. López, ${ }^{2}$ E. Mendizábal, ${ }^{1}$ and J. E. Puig ${ }^{1}$ \\ ${ }^{1}$ Departamentos de Ingeniería Química y Química, CUCEI, Universidad de Guadalajara, Boul. M. García Barragán No. 1431, \\ 44430 Guadalajara, SAL, Mexico \\ ${ }^{2}$ Departamento de Procesos de Polimerización, Centro de Investigación en Química Aplicada, Boulevard Enrique Reyna No. 140, \\ 252294 Saltillo, $\mathrm{CAOH}$, Mexico
}

Correspondence should be addressed to R. G. López, glopez@ciqa.mx

Received 9 February 2012; Revised 28 March 2012; Accepted 2 April 2012

Academic Editor: Alejandro Manzano Ramirez

Copyright () 2012 M. A. Pedroza-Toscano et al. This is an open access article distributed under the Creative Commons Attribution License, which permits unrestricted use, distribution, and reproduction in any medium, provided the original work is properly cited.

\begin{abstract}
Precipitation of silver nanoparticles at $70^{\circ} \mathrm{C}$ was carried out by dosing a $1.3 \mathrm{M}$ sodium borohydride aqueous solution over bicontinuous microemulsions formed with a mixture of sodium bis(2-ethylhexyl) sulfosuccinate (AOT) and sodium dodecylsulfate (SDS) as surfactants, a $0.5 \mathrm{M}$ silver nitrate aqueous solution, and toluene. Weight ratios of 2.5/1 and 3/1 AOT/SDS were used in the precipitation reactions. Silver nanoparticles were characterized by transmission electronic microscopy, X-ray diffraction, and atomic absorption spectroscopy. A mixture of isolated spheroidal nanoparticles $(\approx 15$ wt. $\%)$ with an average diameter around $10 \mathrm{~nm}$ and wormlike structures $(\approx 85 \mathrm{wt} . \%)$ with an average length close to $480 \mathrm{~nm}$ and an average diameter ca. $40 \mathrm{~nm}$ was obtained, regardless of the AOT/SDS ratio. Higher yields were obtained compared with those reported when reverse microemulsions were employed. Formation of wormlike structures was ascribed to one-dimensional aggregation of crystal and particles within the channels of bicontinuous microemulsions, which performed as templates.
\end{abstract}

\section{Introduction}

Reverse microemulsions have been used for several years in precipitation reactions to obtain inorganic nanoparticles of the metals $\mathrm{Cu}, \mathrm{Pd}, \mathrm{Rh}, \mathrm{Ir}, \mathrm{Au}$, and $\mathrm{Pt}$ and of metal compounds such as $\mathrm{Al}(\mathrm{OH})_{3}, \mathrm{Fe}_{3} \mathrm{O}_{4}, \mathrm{TiO}_{2}, \mathrm{~V}_{2} \mathrm{O}_{5}, \mathrm{ZnO}$, and $\mathrm{ZrO}_{2}$ [1]. In these cases the particles precursors are situated in the aqueous phase of a reverse microemulsion, to which another reverse microemulsion containing the precipitating agent or an aqueous solution of the precipitating agent is added, to produce the inorganic nanoparticles [2-8].

Nowadays there is an increasing interest in the preparation and characterization of silver nanoparticles, because of their applications in catalysis $[9,10]$, in nonlinear optical technology, as bactericidal agent $[11,12]$ and in nanosphere lithography [13]. The synthesis of silver nanoparticles with average diameters smaller than $15 \mathrm{~nm}$ and narrow size distributions has been reported by precipitation in reverse microemulsions, but the productivity is usually low ( $\leq 0.4 \mathrm{~g} / 100 \mathrm{~g}$ microemulsion) $[3-5,7,8,14,15]$. To increase the productivity of silver nanoparticles, Sosa et al. [16] used high water-content reverse microemulsions. Lim et al. [17] used bicontinuous microemulsions for obtaining zinc oxide nanoparticles; however, their productivity was not so high (0.7 g nanoparticles $/ 100 \mathrm{~g}$ microemulsion) and the particles were relatively large ( $>150 \mathrm{~nm}$ in average diameter). Also, our group have employed bicontinuous microemulsions with larger water-to-oil ratios than those in reverse microemulsions, to obtain very small nanoparticles of magnetitemaghemite $[18,19]$, zinc oxide $[20,21]$, and silver [22] with diameters smaller than $10 \mathrm{~nm}$ and productivities higher than $1 \mathrm{~g}$ nanoparticles $/ 100 \mathrm{~g}$ microemulsion, which is significantly larger than those obtained when reverse microemulsions were utilized. Recently, Kowlgi et al. [23] obtained platinum 
nanoparticles with average diameters from 1.8 to $18 \mathrm{~nm}$ in bicontinuous microemulsions, depending on the concentration of the platinum precursor aqueous solution.

In the only report, as far as we know, on precipitation of silver nanoparticles in bicontinuous microemulsions, Reyes et al. [22] used microemulsions stabilized with a mixture of AOT/SDS (2/1, w/w) containing $0.5 \mathrm{M}$ silver nitrate $\left(\mathrm{AgNO}_{3}\right)$ aqueous solution, and toluene to obtain a mixture of isolated spheroidal and wormlike nanoparticles. The proportion of the latter decreased as the concentration of the precipitating agent (sodium borohydride) in the aqueous solution added to the microemulsion diminished.

As a continuation of the work of Reyes et al. [22], we report here the preparation of silver nanoparticles in bicontinuous microemulsions stabilized with different AOT/SDS weight ratios and their effect on the morphology and size. Nanoparticles were characterized by transmission electron microscopy (TEM), X-ray diffraction, and atomic absorption spectroscopy.

\section{Materials and Methods}

2.1. Materials. SDS and AOT were $98 \%$ pure from SigmaAldrich. $\mathrm{AgNO}_{3}$ (98.2\% pure from Merck) and toluene (99\% pure from Golden Bell) were used as received. De-ionized and triple-distilled water with conductivity smaller than $6 \mu \mathrm{S} / \mathrm{cm}$ was used.

2.2. Phase Diagram and Electrical Conductivity Determination. The one-phase microemulsion region at the reaction temperature $\left(70^{\circ} \mathrm{C}\right)$ was determined by titrating solutions of AOT/SDS (2.5/1 and 3/1 by weight) in toluene at different surfactant/toluene ratios (in the range of 5 to $65 \mathrm{w} / \mathrm{w}$ ) with a $0.5 \mathrm{M} \mathrm{AgNO}_{3}$ aqueous solution under continuous agitation. The phase boundaries were detected as those compositions where samples became turbid. Samples were also examined with cross-polarizers to rule out liquid crystalline phases that might form. Phase boundaries were checked by preparing samples by weight with compositions above and below the titration-determined phase boundaries in sealed glass vials.

To determine the compositions where bicontinuous microemulsion formed, conductivities of samples along lines A, B, and C, which corresponds to 50/50, 55/45, and 60/40 surfactant mixture-to-toluene weight ratio (Figure 1), were analyzed with a $3173 \mathrm{R}$ JENCO conductivity meter at $70^{\circ} \mathrm{C}$. To prepare silver nanoparticles two compositions in the bicontinuous microemulsion region were used. In both cases, the concentrations of $0.5 \mathrm{M} \mathrm{AgNO}_{3}$ aqueous solution, surfactants mixture, and toluene $(35,39$, and $25 \mathrm{wt} . \%$, resp.) were the same and only the AOT/SDS weight ratio was modified (2.5/1 and 3/1).

2.3. Silver Particles Precipitation. The precipitation reaction was carried out in duplicate at $70^{\circ} \mathrm{C}$ in a $250 \mathrm{~mL}$ jacketed glass reactor equipped with a reflux condenser and an inlet for the sodium borohydride aqueous solution feeding. The procedure for the precipitation reaction started by loading the reactor with the microemulsion $(100 \mathrm{~g})$ and raising the

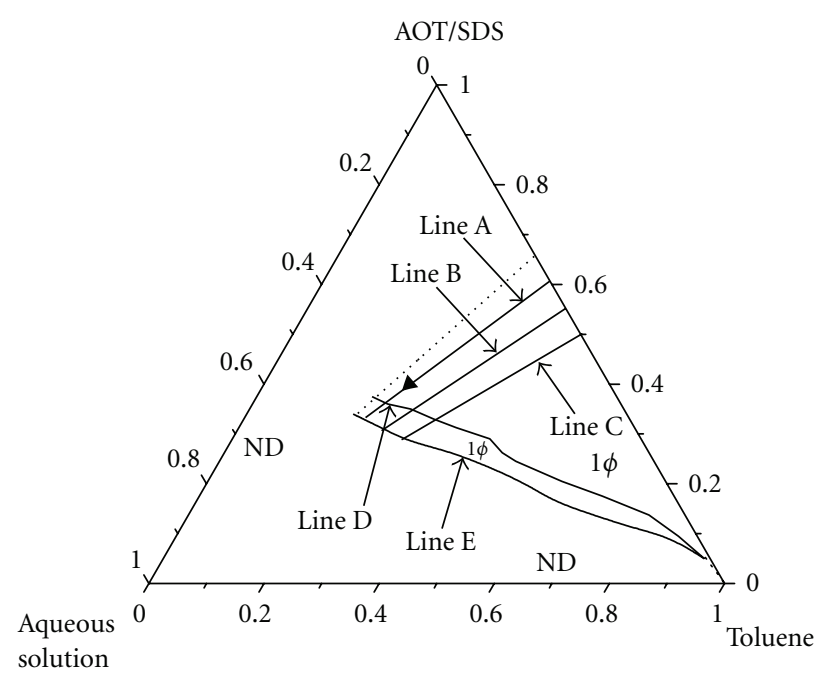

Figure 1: Partial phase diagrams at $70^{\circ} \mathrm{C}$ for mixtures of toluene, $0.5 \mathrm{M} \mathrm{AgNO}_{3}$ aqueous solution, and AOT/SDS weight ratios of $2.5 / 1$ (D) and $3 / 1$ (E). The one-phase microemulsion region is denoted by $1 \phi$. The nondetermined (ND) regions were not examined because they are not interesting for the present work. Lines A, B, and C, indicate the compositions along which electrical conductivity measurements were performed. Solid triangle shows the composition where the precipitation reactions were made.

temperature to $70^{\circ} \mathrm{C}$. Then, a $1.3 \mathrm{M}$ sodium borohydride aqueous solution was dosed at a rate of $0.1 \mathrm{~g} / \mathrm{min}$ for 150 minutes. At these conditions, the molar ratio sodium borohydride/silver nitrate was $10 \%$ higher than the stoichiometric ratio. After completing the sodium borohydride addition, the reaction was allowed to proceed for 30 more minutes and then acetone was added to precipitate the solids, which were allowed to settle for 24 hours. The precipitate was washed at least ten times with a water-acetone solution $(81 / 19, \mathrm{w} / \mathrm{w})$ and then dried in an oven at $60^{\circ} \mathrm{C}$ for 24 hours.

2.4. Characterization. The resulting product, a fine powder, was characterized in a Siemens D-5000 X-ray diffractometer (XRD). Particle size was determined by TEM in a JEOL JEM1010; for this, the resulting powder was dispersed in acetone with an ultrasonicator, and then a drop of the dispersion was deposited on a copper grid, where the solvent was allowed to evaporate. The purity of the final product was determined in a Varian Spectra250 AA atomic absorption spectrometer.

\section{Results and Discussion}

To delimit the region where one-phase microemulsions formed, pseudoternary phase diagrams were obtained. The systems were prepared with a mixture of AOT/SDS at two different weight ratios, toluene, and $0.5 \mathrm{M} \mathrm{AgNO}_{3}$ aqueous solution. Figure 1 shows the pseudoternary phase diagrams for the systems containing mixtures of AOT/SDS with weight ratios of $2.5 / 1$ and $3 / 1$. A slightly larger microemulsion region was obtained when the AOT/SDS ratio of $3 / 1$ was used in the formulation. The microemulsion 
regions obtained with both AOT/SDS ratios extend to the central part of the diagram, which suggests the existence of bicontinuous microemulsions. However, the microemulsion regions do not extend to the water-rich zone of the diagram as it was detected when AOT/SDS $(2 / 1 \mathrm{w} / \mathrm{w})$ mixture was employed [22], which indicates the absence of normal (oilin-water) microemulsions. This can be explained since AOT tends to form inverse micelles and (w/o) microemulsions whereas SDS tends to form normal micelles and $(\mathrm{o} / \mathrm{w})$ microemulsions [24].

Because it is desirable to obtain the largest possible amount of silver nanoparticles, three ratios of surfactants/toluene mixture (50/50, 55/45, and 60/40 w/w), which allows higher concentrations of aqueous solution inside the microemulsion region, were selected. To find the bicontinuous microemulsion region, the content of the $0.5 \mathrm{M}$ aqueous $\mathrm{AgNO}_{3}$ solution was increased while maintaining the ratio of surfactant/toluene constant (lines A, B, and C, in Figure 1) and their electrical conductivities were measured.

Figures 2 and 3 depict the electrical conductivity for the AOT/SDS weight ratios of $2.5 / 1$ and $3 / 1$, respectively, as a function of the amount of the $\mathrm{AgNO}_{3}$ aqueous solution for the three selected surfactants/toluene weight ratios (50/50, 55/45, and 60/40). For the two chosen AOT/SDS weight ratios (2.5/1 and 3/1), the conductivities along the microemulsion region were very low in the cases of $50 / 50$ and 55/45 surfactants/toluene ratios. When the 60/40 surfactants/toluene weight ratio was used and the AOT/SDS weight ratio was $3 / 1$, the microemulsion conductivity started to rise when the $\mathrm{AgNO}_{3}$ aqueous solution concentration was around $22.5 \mathrm{wt} . \%$, reaching a maximum of $1900 \mu \mathrm{S} / \mathrm{cm}$ at around $40 \mathrm{wt} . \%$, followed by a conductivity drop. For the microemulsions prepared with the 2.5/1 AOT/SDS weight ratio, the electrical conductivity started to increase at about $20 \mathrm{wt} . \% \mathrm{AgNO}_{3}$ aqueous solution; then the conductivity increased steeply and reached a maximum $(4400 \mu \mathrm{S} / \mathrm{cm})$ at a concentration of about $38 \mathrm{wt} . \%$. In this case a drop in electrical conductivity could not be detected because the conductivity was not measured at aqueous $\mathrm{AgNO}_{3}$ solution concentrations higher than $40 \mathrm{wt} . \%$, because at this aqueous solution concentration, microemulsions do not form. According to the percolation theory, bicontinuous microemulsions show a high conductivity as a result of having continuous (or connected) aqueous phase domains [25-28]. In contrast, reverse microemulsions are very poor electrical conductors because of their discontinuous microstructure [25-28]. From the results obtained here, it follows that bicontinuous microemulsions form at a surfactants/toluene ratio of $60 / 40(\mathrm{w} / \mathrm{w})$ and AOT/SDS weight ratios of $2.5 / 1$ and $3 / 1$. When the former ratio is used, bicontinuous microemulsions develop in the range from 2530 to $40 \mathrm{wt} . \% \mathrm{AgNO}_{3}$ aqueous solution; in the latter case, the span of the bicontinuous microemulsion region ranges from 27.5-30 to 45 wt. $\% \mathrm{AgNO}_{3}$ aqueous solution.

Precipitation reactions were carried out in bicontinuous microemulsions containing $35 \mathrm{wt} . \% 0.5 \mathrm{M} \mathrm{AgNO}_{3}$ aqueous solution and AOT/SDS weight ratios of $2.5 / 1$ and $3 / 1$. The appearance of the precursor microemulsions was yellowishtranslucent but then they turned black with the addition

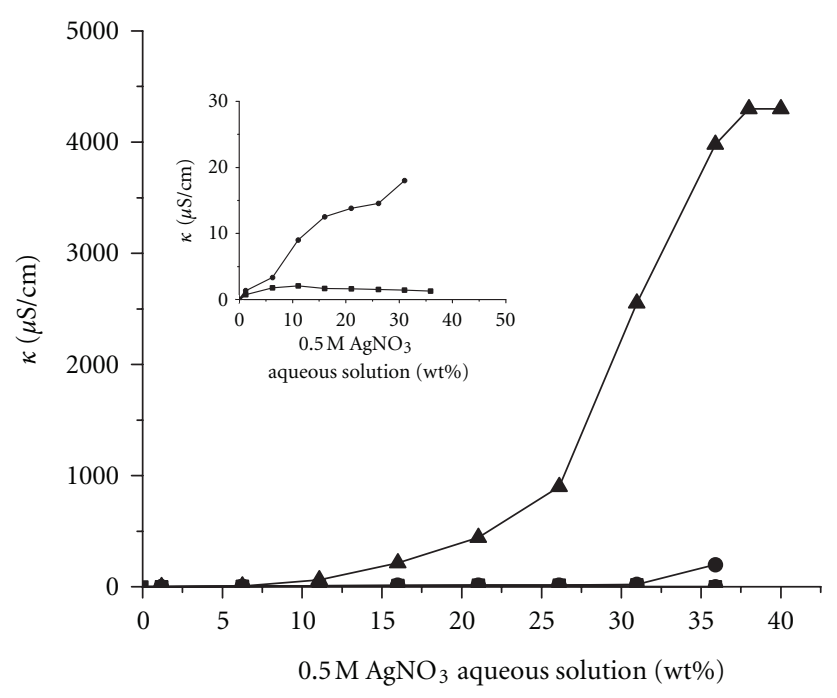

FIGURE 2: Electrical conductivity of the one-phase microemulsions versus concentration of $0.5 \mathrm{M} \mathrm{AgNO}_{3}$ aqueous solutions for AOT/SDS weight ratios of 2.5/1 and ratios of surfactants/toluene

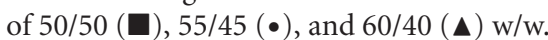

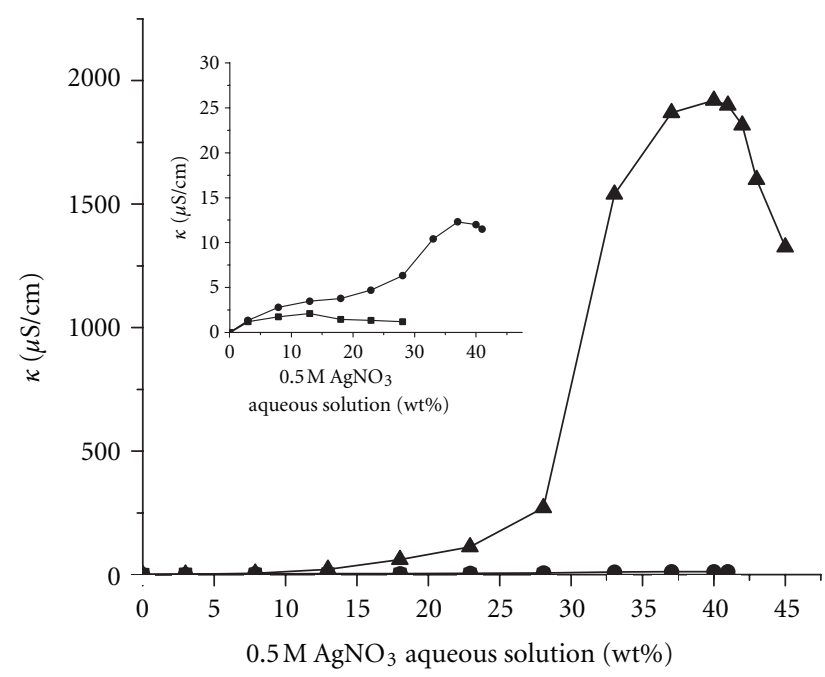

FIGURE 3: Electrical conductivity of the one-phase microemulsions versus concentration of $0.5 \mathrm{M} \mathrm{AgNO}_{3}$ aqueous solutions for AOT/SDS weight ratios of $3 / 1$ and ratios of surfactants/toluene of

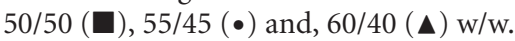

of the $\mathrm{NaBH}_{4}$ aqueous solution. At the end of the reaction, the product (a grayish-black powder) was recovered, obtaining productivities of ca. $1.5 \mathrm{~g} \mathrm{Ag} / 100 \mathrm{~g}$ microemulsionprecipitating agent mixture and yields higher than $85 \%$ (Table 1) as determined by atomic absorption spectroscopy. When only the bicontinuous microemulsion is considered, the productivity is $1.7 \mathrm{~g} \mathrm{Ag} / 100 \mathrm{~g}$ microemulsion. This productivity is larger than the largest one calculated from the data in those reports that employed reverse microemulsions (0.4 $\mathrm{g}$ of Ag/100 g microemulsion) [4].

Figure 4 shows the X-ray diffraction pattern (XRDP) of the $\mathrm{Ag}$ nanoparticles obtained from microemulsions 
TABLE 1: Ag nanoparticles purity, productivity and yield of the precipitation reactions.

\begin{tabular}{lccr}
\hline AOT/SDS weight ratio & Ag purity $(\%)$ & Productivity $(\mathrm{g} \mathrm{Ag} / 100$ g reaction mixture $)$ & Yield $(\%)$ \\
\hline $2.5 / 1$ & $93.76 \pm 1.26$ & $1.59 \pm 0.06$ & $91.34 \pm 3.25$ \\
$3 / 1$ & $93.58 \pm 1.54$ & $1.48 \pm 0.04$ & $85.05 \pm 2.44$ \\
\hline
\end{tabular}

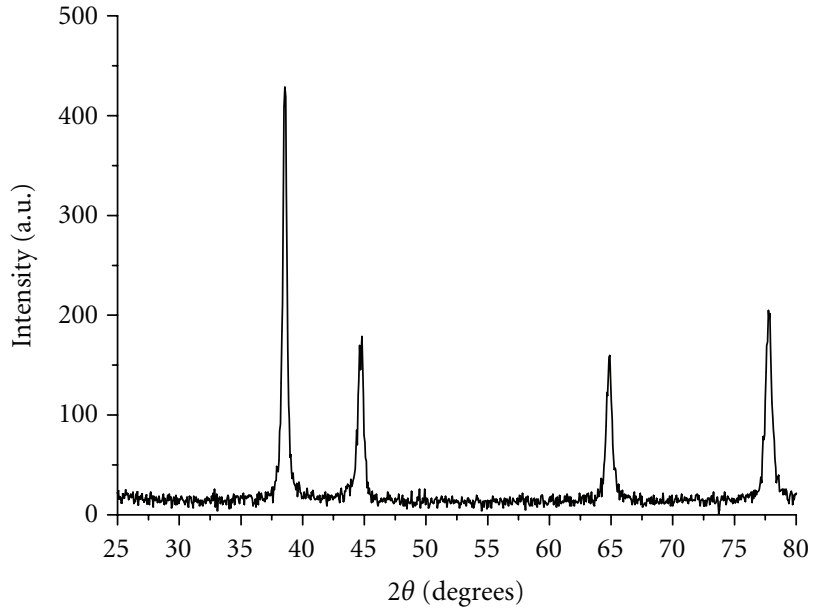

(a)

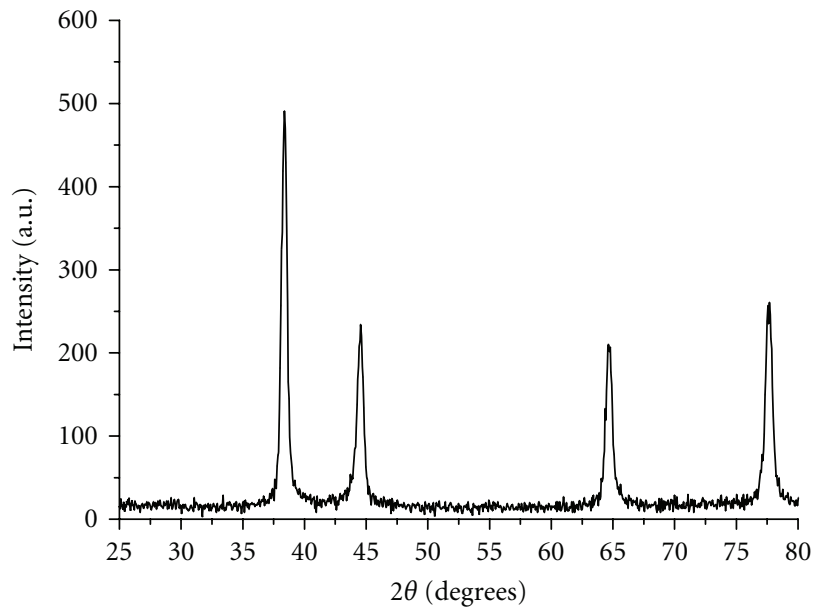

(b)

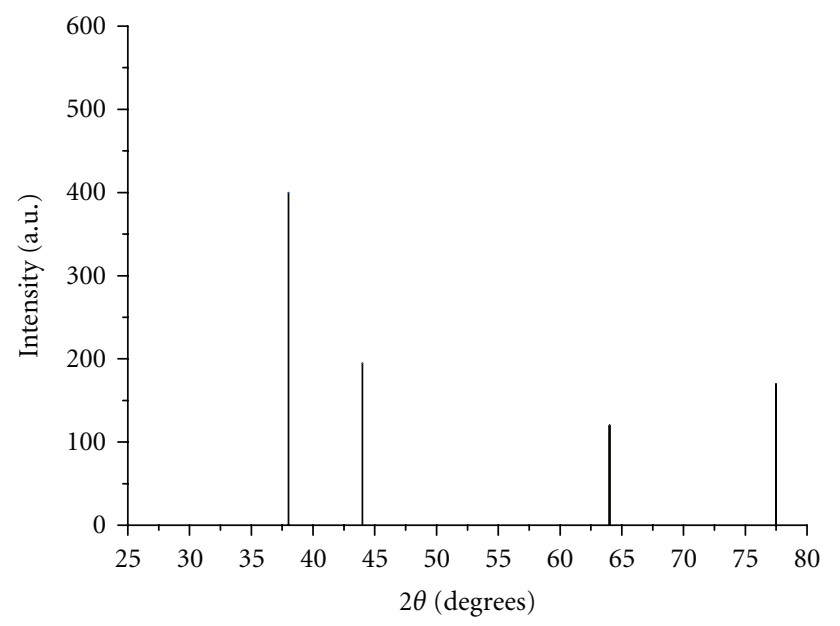

(c)

FIGURE 4: X-ray diffraction patterns for the precipitation reactions carried out at 2.5/1 (a) and 3/1 (b) AOT/SDS weight ratios. Standard pattern of silver is included (c).

made with the AOT/SDS weight ratios of 2.5 and 3/1 and the Ag-standard XRDP (JCPDS card file number 893722). The XRDPs of the Ag nanoparticles show the major four characteristic signals of silver crystal (at 38.14, 44.32, 64.60, and $77.442 \theta^{\circ}$ ), which corresponds to the face-centered cubic phase of pure silver nanoparticles.

An estimation of the average crystal size of the particles obtained in the precipitation reactions was made with the data from their XRDPs (Figure 4) and the well-known Scherrer equation:

$$
d=\frac{K \lambda}{\beta \cos \theta}
$$

where $d$ is the mean diameter of grain in nm, $K$ is the dimensional factor (0.9), $\lambda$ is the $\mathrm{X}$-ray wavelength $(0.154 \mathrm{~nm}), \beta$ is the line broadening at half the maximum intensity in radians, and $\theta$ is the Bragg's angle. Values of $d$ of $17.85 \pm 1.13$ and $13.60 \pm 1.90 \mathrm{~nm}$ for the precipitations carried out using the AOT/SDS ratios of 2.5/1 and 3/1, respectively, were obtained. According to this, the later AOT/SDS ratio limits to some extent crystal growth, probably because the higher content of AOT leads to a decrease in the diameter of the channels in the microemulsion, reducing the number of the Ag atoms in the vicinity of the nuclei.

Figure 5 depicts representative micrographs of the products prepared with AOT/SDS weight ratios of 2.5/1 and $3 / 1$ along with their corresponding histograms of particle 

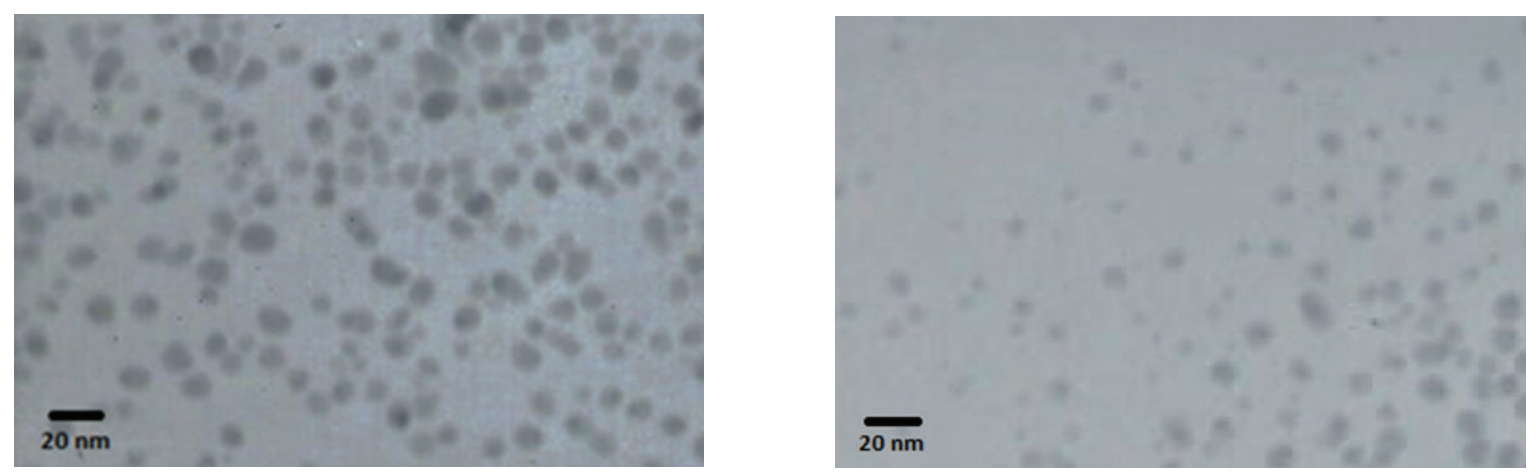

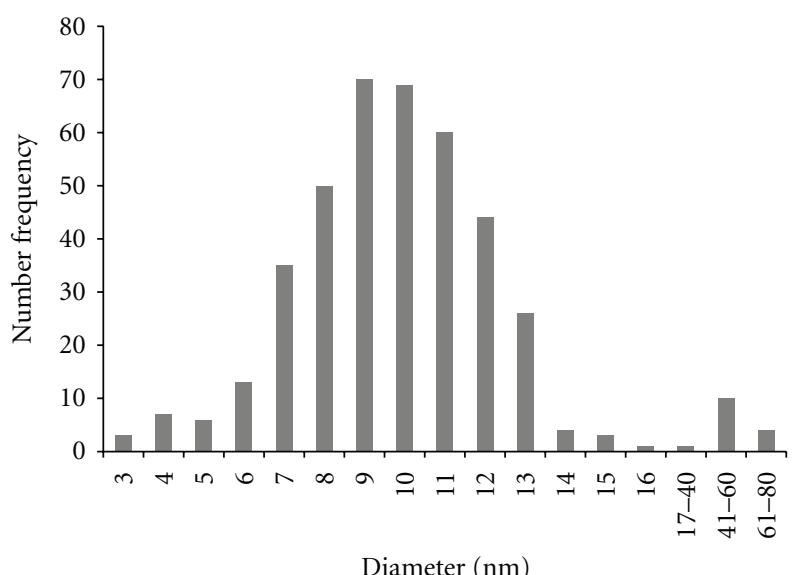

(a)

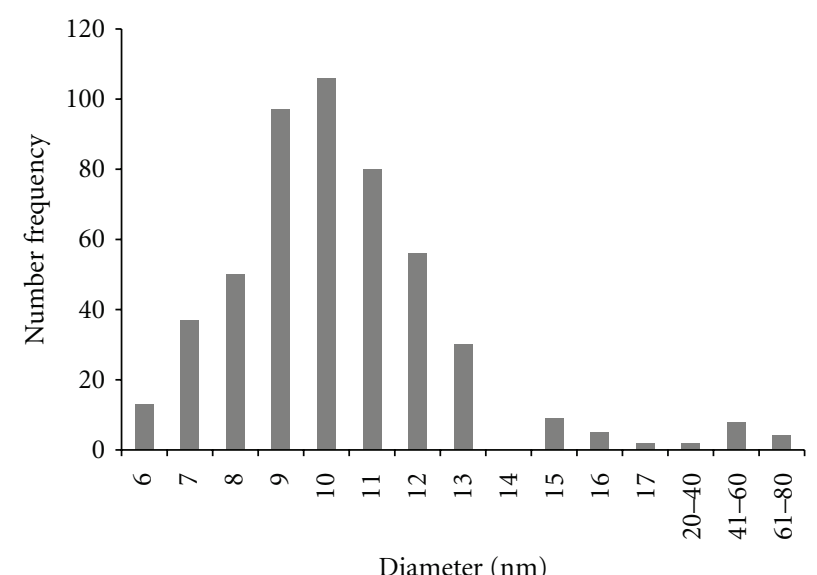

(b)

FIGURE 5: TEM micrographs and their histograms for particles obtained from precipitation at $70^{\circ} \mathrm{C}$ in bicontinuous microemulsions containing 35 wt.\% $0.5 \mathrm{M} \mathrm{AgNO}_{3}$ aqueous solution and $39 \mathrm{wt} . \%$ AOT/SDS weight ratios of 2.5 (a) and 3/1 (b).

diameters obtained measuring over 500 particles. Most of the particles were isolated spheroids; however, a few wormlike particles were also observed (Figure 6). These histograms indicate that there are two particle populations: one including particles with diameters $\leq 16 \mathrm{~nm}$, which was determined by measuring only the isolated spheroidal nanoparticles, and another one that includes larger particles (from 17 to $80 \mathrm{~nm}$ in diameter), which are forming the wormlike structures. Furthermore, the length of the worms was measured. Table 2 shows the average dimensions of the isolated spheroidal nanoparticles and of the wormlike nanoparticles as well as the number and weight fraction of the latter in the final product mixture. For the weight fraction calculation reported in Table 2, the isolated spheroidal nanoparticles were taken as perfect spheres, while wormlike nanoparticles were considered as cylinders. Then, the particles volume was calculated, and with the measured number proportion of spheroid and wormlike nanoparticles (Table 2) and the silver density, the weight fraction of each type of structure was estimated. Table 2 discloses that the isolated spheroidal nanoparticles have diameters of ca. $10 \mathrm{~nm}$, whereas the wormlike structures show average lengths of around $480 \mathrm{~nm}$ and average diameters close to $40 \mathrm{~nm}$. Although the number of larger particles is small $(<3 \%)$, they represent 84 to $87 \mathrm{wt} . \%$. Furthermore, data from Table 2 indicate that there is not statistical effect of the AOT/SDS ratio studied in this work on the morphology and size. However, there is a great difference between these results and those obtained in our previous work [22], where practically only isolated spheroidal nanoparticles with $3 \mathrm{~nm}$ in average diameter were obtained. In that work also a low concentration of $\mathrm{NaBH}_{4}$ aqueous solution was used, but microemulsions were stabilized with a lower AOT/SDS weight ratio (2/1). An explanation of the differences between the results reported here and those of Reyes et al. [22] would arise from the increase in the proportion of AOT molecules in the surfactant layer, which diminished the protector effect of this layer during the inter-channel collisions, leading to a an increase in the fusion-fission rate during $\mathrm{Ag}$ particle formation and, consequently, on the nanoparticles coalescence, giving more wormlike nanostructures.

A comparison of the nanostructures dimensions determined by TEM with those calculated from X-ray data indicates that the average diameter of the isolated spheroidal nanoparticles $(\approx 10 \mathrm{~nm})$ is smaller than the average crystal diameters (17.9 and $13.6 \mathrm{~nm}$ for AOT/SDS weight ratio, $2.5 / 1$ and $3 / 1$, resp.). This suggests that each nanoparticle in the population of isolated spheroidal structures is formed of a single crystal. In contrast, the wormlike nanoparticles, the dimensions of which are much higher than the average crystal diameter, are formed by aggregation of crystals. This aggregation arises from the fact that crystals and particles 
TABLE 2: Average sizes of silver nanoparticles and composition of the final mixture.

\begin{tabular}{|c|c|c|c|c|c|}
\hline \multirow{2}{*}{$\begin{array}{l}\text { AOT/SDS weight } \\
\text { ratio }\end{array}$} & \multirow{2}{*}{$\begin{array}{c}\text { Spheroidal } \\
\text { nanoparticles } \\
D_{n}(\mathrm{~nm})\end{array}$} & \multicolumn{4}{|c|}{ Wormlike nanoparticles } \\
\hline & & $\begin{array}{c}\text { Average } \\
\text { diameter }(\mathrm{nm})\end{array}$ & $\begin{array}{l}\text { Average length } \\
(\mathrm{nm})\end{array}$ & $\begin{array}{c}\text { Average number } \\
\text { percent }\end{array}$ & $\begin{array}{c}\text { Average weight } \\
\text { percent }\end{array}$ \\
\hline $2.5 / 1$ & $10.18 \pm 1.95$ & $43 \pm 17.55$ & $490 \pm 205$ & $2.6 \pm 1.2$ & $86.7 \pm 2.45$ \\
\hline $3 / 1$ & $9.64 \pm 2.05$ & $38.00 \pm 15.34$ & $465 \pm 181$ & $2.7 \pm 0.2$ & $84.4 \pm 2.87$ \\
\hline
\end{tabular}

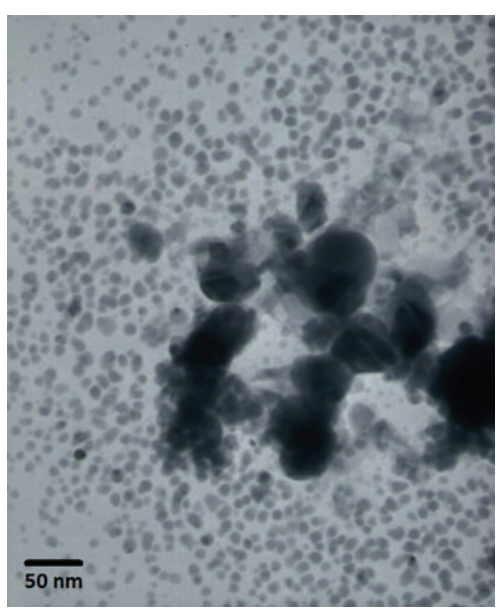

FIGURE 6: Representative micrograph of wormlike nanostructures obtained in precipitation reactions.

within the channels of bicontinuous microemulsions are not protected with a surfactant layer, as they are in the case of precipitation in reverse microemulsions. This condition favors the crystal and particle aggregation as a consequence of collisions between these structures. Moreover, because microemulsions channels act as templates, one-dimensional aggregation would be expected, forming the wormlike structures.

\section{Conclusions}

Silver nanoparticles with two particle size populations were obtained by precipitation in bicontinuous microemulsions. The productivity of silver nanoparticles obtained by this method was around $1.5 \mathrm{~g}$ silver nanoparticles $/ 100 \mathrm{~g}$ microemulsion-precipitating agent mixture, which is higher than those reported with reverse microemulsions. The structures forming the smaller particles population were isolated spheroids with an average diameter of $10 \mathrm{~nm}$, which represents around $15 \%$ of the total weight of the nanoparticles. The larger particles composing the other population were wormlike structures with an average length of $480 \mathrm{~nm}$ and average diameter of $40 \mathrm{~nm}$ and although they are only $3 \%$ of the total number of particles, they represent around $85 \%$ of the total weight of the obtained Ag nanostructures. No statistical effect of AOT/SDS ratio on morphology and particle size was identified. Formation of wormlike structures was ascribed to a one-dimensional aggregation of crystals and particles within the microemulsion channels, which would arise from these nanostructures acting as templates.

\section{Acknowledgments}

This work was supported by FOMIXJAL (Grant no. 200905-124211) and CONACYT (Grants no. CB-2007-82437 and CB-2007-84009). One of the authors (M. A. PedrozaToscano) acknowledges the scholarship from CONACYT. The authors are grateful to Alejandro Espinoza and Blanca Huerta for their technical assistance in characterization work.

\section{References}

[1] K. Osseo-Asare, Handbook of Microemulsion Science and Technology, Marcel Dekker, New York, NY, USA, 1999.

[2] P. Barnickel and A. Wokaun, "Synthesis of metal colloids in inverse microemulsions," Molecular Physics, vol. 69, no. 1, pp. 1-9, 1990.

[3] C. Petit, P. Lixon, and M. P. Pileni, "In situ synthesis of silver nanocluster in AOT reverse micelles," Journal of Physical Chemistry, vol. 97, no. 49, pp. 12974-12983, 1993.

[4] L. A. Pavlyukhina, T. O. Zaikova, G. V. Odegova, S. A. Savintseva, and V. V. Boldyrev, "Silver cluster and nanoparticles: preparation in water-in-oil microemulsions and some physical properties," Inorganic Materials, vol. 34, no. 2, pp. 109-113, 1998.

[5] Z. Zhang, R. C. Patel, R. Kothari, C. P. Johnson, S. E. Friberg, and P. A. Aikens, "Stable silver clusters and nanoparticles prepared in polyacrylate and inverse micellar solutions," Journal of Physical Chemistry B, vol. 104, no. 6, pp. 1176-1182, 2000.

[6] W. Zhang, X. Qiao, and J. Chen, "Synthesis and characterization of silver nanoparticles in AOT microemulsion system," Chemical Physics, vol. 330, no. 3, pp. 495-500, 2006.

[7] W. Zhang, X. Qiao, J. Chen, and H. Wang, "Preparation of silver nanoparticles in water-in-oil AOT reverse micelles," Journal of Colloid and Interface Science, vol. 302, no. 1, pp. 370373, 2006.

[8] W. Zhang, X. Qiao, and J. Chen, "Synthesis of nanosilver colloidal particles in water/oil microemulsion," Colloids and Surfaces A, vol. 299, no. 1-3, pp. 22-28, 2007.

[9] N. Pradhan, A. Pal, and T. Pal, "Silver nanoparticle catalyzed reduction of aromatic nitro compounds," Colloids and Surfaces A, vol. 196, no. 2-3, pp. 247-257, 2002.

[10] H. Nakatsuji, H. Nakai, K. Ikeda, and Y. Yamamoto, "Mechanism of the partial oxidation of ethylene on an Ag surface: dipped adcluster model study," Surface Science, vol. 384, no. 1-3, pp. 315-333, 1997. 
[11] Q. L. Feng, J. Wu, G. Q. Chen, F. Z. Cui, T. N. Kim, and J. O. Kim, "A mechanistic study of the antibacterial silver ions on Escherichia coli and Staphylococcus aureus," Journal of Biomedical Materials Research, vol. 52, no. 4, pp. 662-668, 2000.

[12] J. W. Kim, J. E. Lee, S. J. Kim et al., "Synthesis of silver/polymer colloidal composites from surface-functional porous polymer microspheres," Polymer, vol. 45, no. 14, pp. 4741-4747, 2004.

[13] J. C. Hulteen, D. A. Treichel, M. T. Smith, M. L. Duval, T. R. Jensen, and R. P. Van Duyne, "Nanosphere lithography: sizetunable silver nanoparticle and surface cluster arrays," Journal of Physical Chemistry B, vol. 103, no. 19, pp. 3854-3863, 1999.

[14] J. N. Solanki and Z. V. P. Murthy, "Highly monodisperse and sub-nano silver particles synthesis via microemulsion technique," Colloids and Surfaces A, vol. 359, no. 1-3, pp. 31$38,2010$.

[15] X. Wu, T. Wang, and H. Wu, "Facile preparation and formation mechanism of uniform silver nanoparticles using OP-10 as emulsifier in reverse microemulsion," Journal Wuhan University of Technology, Materials Science Edition, vol. 26, no. 1, pp. 38-42, 2011.

[16] Y. D. Sosa, M. Rabelero, M. E. Treviño, H. Saade, and R. G. López, "High-yield synthesis of silver nanoparticles by precipitation in a high-aqueous phase content reverse microemulsion," Journal of Nanomaterials, vol. 2010, Article ID 392572, 6 pages, 2010.

[17] B. P. Lim, J. Wang, S. C. Ng, C. H. Chew, and L. M. Gan, "A bicontinuous microemulsion route to zinc oxide powder," Ceramics International, vol. 24, no. 3, pp. 205-209, 1998.

[18] J. Esquivel, I. A. Facundo, M. E. Treviño, and R. G. López, "A novel method to prepare magnetic nanoparticles: precipitation in bicontinuous microemulsions," Journal of Materials Science, vol. 42, no. 21, pp. 9015-9020, 2007.

[19] A. L. Loo, M. G. Pineda, H. Saade, M. E. Treviño, and R. G. López, "Synthesis of magnetic nanoparticles in bicontinuous microemulsions. Effect of surfactant concentration," Journal of Materials Science, vol. 43, no. 10, pp. 3649-3654, 2008.

[20] S. López-Cuenca, L. A. Pérez Carrillo, M. Rabelero Velasco et al., "High-yield synthesis of zinc oxide nanoparticles from bicontinuous microemulsions," Journal of Nanomaterials, vol. 2011, Article ID 431382, 6 pages, 2011.

[21] L. E. Romo, H. Saade, B. Puente, M. L. López, R. Betancourt, and R. G. López, "Precipitation of zinc oxide nanoparticles in bicontinuous microemulsions," Journal of Nanomaterials, vol. 2011, Article ID 145963, 9 pages, 2011.

[22] P. Y. Reyes, J. A. Espinoza, M. E. Treviño, H. Saade, and R. G. López, "Synthesis of silver nanoparticles by precipitation in bicontinuous microemulsions," Journal of Nanomaterials, vol. 2010, Article ID 948941, 7 pages, 2010.

[23] K. Kowlgi, U. Lafont, M. Rappolt, and G. Koper, "Uniform metal nanoparticles produced at high yield in dense microemulsions," Journal of Colloid and Interface Science, vol. 372, no. 1, pp. 16-23, 2012.

[24] J. N. Israelachvili, Intermolecular and Surface Forces, Academic Press, San Diego, Calif, USA, 2nd edition, 1991.

[25] H. F. Eicke, M. Borkovec, and B. Das-Gupta, "Conductivity of water-in-oil microemulsions: a quantitative charge fluctuation model," Journal of Physical Chemistry, vol. 93, no. 1, pp. 314317, 1989.

[26] M. Borkovec, H. F. Eicke, H. Hammerich, and B. Das Gupta, "Two percolation processes in microemulsions," Journal of physical chemistry, vol. 92, no. 1, pp. 206-211, 1988.
[27] J. F. Billman and E. W. Kaler, "Structure and phase behavior in five-component microemulsions," Langmuir, vol. 6, no. 3, pp. 611-620, 1990.

[28] A. Maitra, C. Mathew, and M. Varshney, "Closed and open structure aggregates in microemulsions and mechanism of percolative conduction," Journal of Physical Chemistry, vol. 94, no. 13, pp. 5290-5292, 1990. 

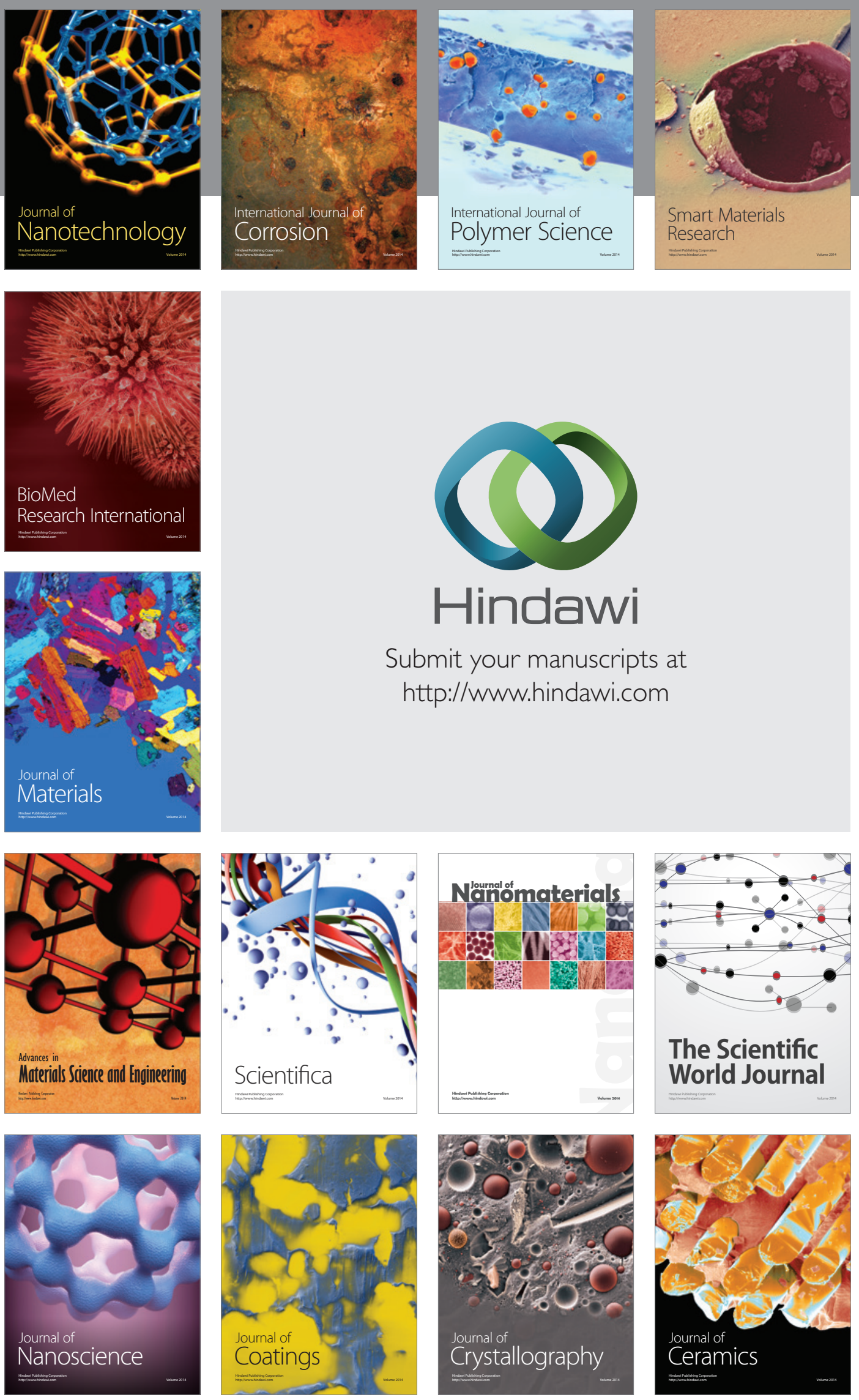

The Scientific World Journal

Submit your manuscripts at

http://www.hindawi.com

\section{World Journal}

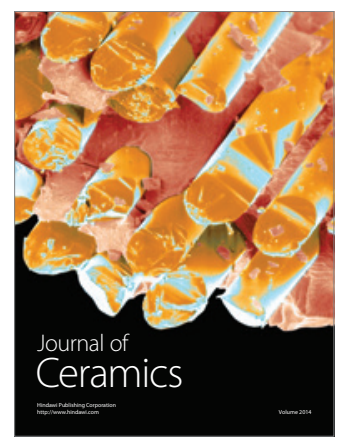

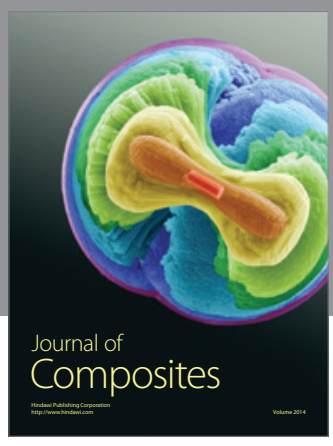
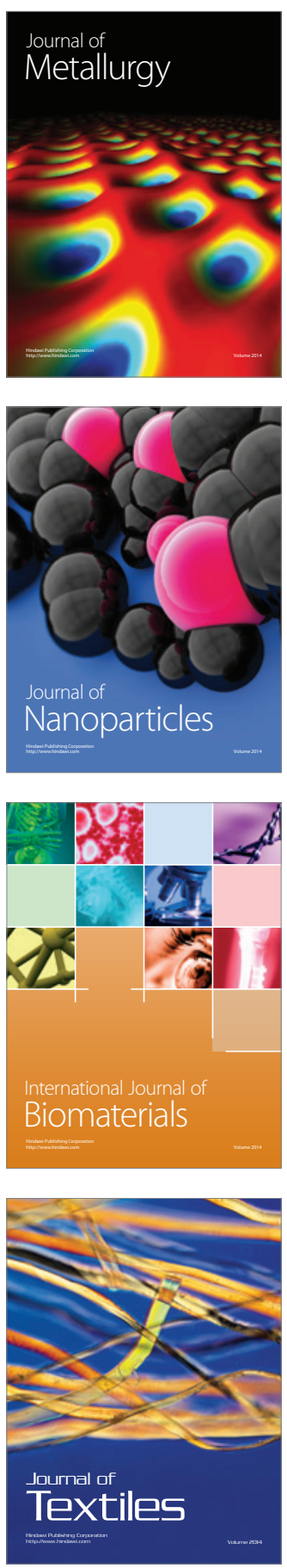